polarizers which are not parallel. The results with parallel polarizers are easily explicable along Einsteinian lines. The results with off-parallel polarizers are not. That is the new point, unknown to EPR, which inspired the experimental programme of recent years to which the author seems to refer.

While I claim that Professor Davies is wrong on these points, it would certainly be unjust to pillory him on account of them. He makes these mistakes, if they are indeed mistakes, in the company of many other distinguished physicists. He could claim to be reporting a consensus! I enjoyed the book, despite all the reservations, and expect it to be enjoyed by many. The author provides a lively account, accessible with very little technical background, of what is being said about some momentous and inevitable questions. And if he sometimes leads into error, he does not lead into a minority.

J. S. Bell is a physicist working at CERN in Geneva.

\section{Data book on zinc}

\section{Roy M. Harrison}

Zinc in the Environment. Edited by J. O. Nriagu. Part 1 Ecological Cycling, pp.453; Part 2 Health Effects, pp.480. (WileyInterscience: 1980.) Each volume $£ 27.50$, $\$ 59.85$.

MOST non-specialists will probably associate the subject of metals in the environment with possible adverse human health effects; indeed in the cases of metals such as lead, cadmium and mercury the main stimulus for research has arisen from concerns over toxic symptoms arising from excessive environmental exposure. Zinc provides a very different case, however. Adverse health effects found in the general population result more often from zinc deficiency, rather than from toxicity due to elevated exposure. Indeed, despite the ubiquitousness of zinc in our environment, numerous well-documented cases of serious zinc deficiency syndrome have arisen amongst groups of people in many different parts of the world. Instances of zinc intoxication in humans are comparatively rare, arising only from extreme exposure conditions not normally experienced by the general population, and in some instances probably due to the cadmium impurity invariably present in technical-grade zinc.

The essentiality of zinc in mammalian metabolism coupled with its considerable toxicity, especially to aquatic biota, make the study of zinc in the environment an important matter which has been rather neglected in comparison with the intensive research efforts expended upon other environmental metals. This two-volume compilation by Nriagu may help to redress the balance; it is an extremely valuable collection of both factual information and numerical data on environmental zinc, and provides a useful source book

Part I covers the production and uses of zinc, the environmental concentrations and pathways of the metal and its cycling within, and effects upon, near-shore marine, freshwater and forest ecosystems. Part II deals primarily with human health effects of zinc, but also includes the effects of zinc upon terrestrial and aquatic flora and fauna.
As in other recent books edited by Nriagu, the emphasis is upon detailed, but frequently uncritical reviews of the literature. Contributions are drawn from a large number of specialist authors and are fairly well up to date, with references up to 1978 included. The editor has imposed a fairly high degree of uniformity of style, and the book gives wide coverage of the topic with few omissions or overlaps. In these regards the book is of far greater value to the reader than the now-common review volumes cobbled together from the proceedings of a symposium and purporting to provide complete coverage of a topic.

Zinc in the Environment cannot be recommended as light reading for the individual requiring a brief overview of the subject. It will, however, be regarded as essential by many research workers in the field and will, in my view, represent an invaluable source of information for a good many years to come.

Roy M. Harrison is a Lecturer in the Department of Environmental Sciences at the University of Lancaster.

\title{
En route to a classic of ornithology
}

\section{Raymond O'Connor \\ Handbook of the Birds of Europe, the Middle East and North Africa: The Birds of the Western Palearctic. Vol.II. Edited by Stanley Cramp. Pp.695. (Oxford University Press: 1980.) $£ 30, \$ 85$.}

THIS is the second volume of The Birds of the Western Palearctic, the ambitious multi-volume work intended as the successor to Witherby's Handbook of British Birds, though with a wider geographical brief than the British Isles of the 1939 work.

The success of Vol.I testifies to the overwhelming acceptance of its general approach and format, and Vol.II follows the same pattern. The volume treats those species belonging to the Accipitriformes, Falconiformes, Galliformes and Gruiformes. Each species account begins with a general consideration of field characters followed by detailed discussion

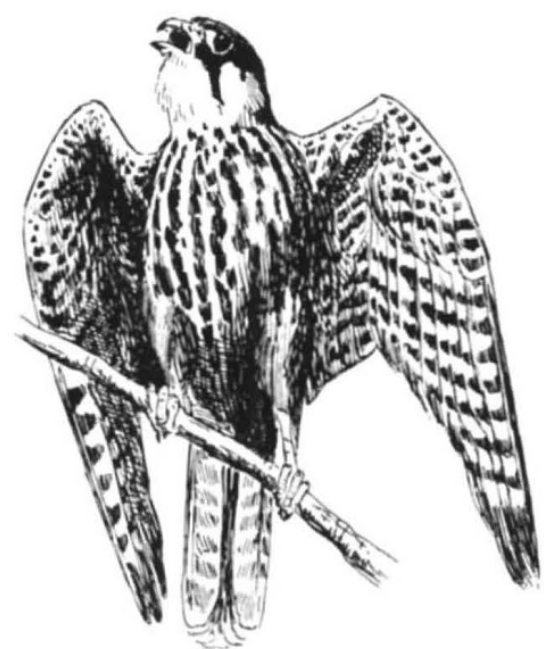

of the plumage characteristics of the recognizable age-classes. Sections on habitat, distribution, population, movements, food, behaviour and breeding follow, and each account is concluded with a listing of plumage and morphology data. The approach is entirely specific except for brief introductions to each family. The editors have rightly persisted with the format of Vol.I with only minor modifi- cations, though I wish they would quote author initials when citing authors of the same surname. Another minor irritant is the failure to reproduce the explanatory material given in the first volume. As a reference work the Handbook should not require one to consult two hefty tomes to locate one's target information within Vol.II.

One general feature of this work is that its treatment of a topic is determined very much by the nature of the material available. For the kestrel, Falco tinnunculus, for example, nest site frequencies are tabulated for German and British studies, regional differences are described between northern and southern Britain, seasonal variation in clutch size is cited on the basis of a Swiss study, egg loss rates are quantified for Dutch and English populations, and breeding success to food supply correlations are mentioned for a Norwegian study. With the Western Palearctic as their geographical remit, the authors are entitled to their use of studies from different areas but I find two shortcomings in this approach. First, is the reader to assume that effects cited in a regional study are common to the whole 